05

\title{
Определение плазменных колебаний в металлах методом полного внешнего отражения рентгеновских лучей
}

\author{
(C) В.М. Стожаров
}

Российский государственный педагогический университет им. А.И. Герцена, 191186 Санкт-Петербург, Россия

e-mail: gut1111@yandex.ru

Поступило в Редакцию 8 февраля 2018 г.

В окончательной редакции 8 февраля 2018 г.

Принято к публикации 4 фревраля 2019 г.

Предложено определение плазменных колебаний в металлах методом полного внешнего отражения (ПВО) рентгеновских лучей. Показана возможность расчета энергии плазмонов, концентрации электронов проводимости и энергии Ферми из экспериментально измеренных скользящих углов падения рентгеновских лучей, испытавших ПВО. Наблюдаются зависимости этих характеристик от определенных кристаллографических направлений и в отдельных случаях наблюдаются зависимости этих характеристик от глубины формирования ПВО.

DOI: $10.21883 / J T F .2019 .07 .47794 .51-18$

\section{Введение}

В 50-е г. Бом и Пайнс [1,2] разработали теорию взаимодействующих электронов твердых тел. Они показали, что коллективное поведение квантовой электронной плазмы твердого тела проявляется в виде плазменных колебаний - плазмонов с энергией $E_{p}=\hbar \omega$. Наряду с классическими исследованиями плазмонов по характеристическим потерям отраженных электронов средних энергий от металлов [3-5], в последние десятилетия началось детальное теоретическое и экспериментальное исследование оптических свойств поверхностных плазмонов в островковых пленках и в ультрадисперсных металлических средах [6-8]. Эти исследования послужили основой создания оптического поверхностно-плазмонного микроскопа, широко применяющегося в настоящее время в биологии и медицине [9]. В обзоре [10] указывается на возможность измерения плазменных частот материалов с помощью полного внешнего отражения (ПВО) рентгеновских лучей.

На основе экспериментальных данных по ПВО различных поликристаллических металлов, полученных в работах $[11,12]$ для разных кристаллографических плоскостей, в настоящей работе представлены результаты расчетов энергии плазмонов, возбужденных рентгеновским излучением $\mathrm{Cu} K_{\alpha 1}$ с энергией кванта $8047 \mathrm{eV}$ в условиях полного внешнего отражения рентгеновских лучей, а также результаты расчетов концентраций электронов проводимости и энергий Ферми. Детали эксперимента подробно изложены в работе [11].

\section{Теоретические представления}

В одноэлектронном приближении на основе теории металлов Друде-Лоренца [13] статическая проводи- мость $\sigma_{0}$ (при частоте электромагнитного поля $\omega=0$ ) определяется соотношением

$$
\sigma_{0}=\frac{N e^{2} \tau}{m},
$$

где $N$ - электронная плотность, $e$ и $m-$ заряд электрона и его масса соответственно, $\tau$ - время релаксации электрона проводимости (т. е. время между двумя последовательными столкновениями этого электрона с ионами кристаллической решетки металла).

Из формулы (1) по удельным сопротивлениям $\rho=1 / \sigma \sim 10^{-8} \Omega \cdot \mathrm{m}$ для металлов, взятым из таблиц Кэй и Лэби [14], рассчитанная величина времени релаксации $\tau$ составляет порядка $10^{-14} \mathrm{~s}$. Высокочастотная проводимость по электронной теории металлов $[13,15]$ является комплексной величиной и выражается соотношением, которое включает зависимость проводимости от частоты электромагнитного поля $\omega$ :

$$
\sigma(\omega)=\frac{\sigma_{0}}{1-i \omega \tau}
$$

где $\sigma_{0}-$ статическая проводимость, определяемая формулой (1). Из уравнений Максвелла для высокочастотных электромагнитных полей функция диэлектрической проницаемости $\varepsilon(\omega)$ так же, как и высокочастотная проводимость, является комплексной величиной и с учетом формулы (2) определяется соотношением

$$
\varepsilon(\omega)=1+\frac{4 \pi i \sigma_{0}}{\omega(1-i \omega \tau)} .
$$

Для используемого в настоящей работе мягкого рентгеновского излучения $\mathrm{Cu} K_{\alpha 1}$ с длиной волны $\lambda=1.5406 \AA$ и соответственно $\mathrm{c}$ угловой частотой $\omega=2 \pi c / \lambda \sim 10^{19} \mathrm{~s}^{-1}$, где $c-$ скорость света, и с учетом сделанной выше оценки величины $\tau$ для металлов произведение в формуле (3) $\omega \tau$ составляет порядка 
$10^{5} \gg 1$. Следовательно, единицей в знаменателе формулы (3) можно пренебречь и поэтому функция $\varepsilon(\omega)$ становится вещественной. С учетом формулы (1) она выражается простым соотношением [16]:

$$
\varepsilon(\omega)=1-\frac{4 \pi \sigma_{0}}{\omega^{2} \tau}=1-\frac{\omega_{p}^{2}}{\omega^{2}}=1-\frac{E_{p}^{2}}{E^{2}},
$$

где, согласно теории плазмонов $[13,15,16], \omega_{p}^{2}=\frac{4 \pi N e^{2}}{m}-$ квадрат угловой частоты плазменных колебаний электронов проводимости; $E_{p}=\hbar \omega_{p}-$ энергия плазмона; $E=8047 \mathrm{eV}$ - энергия падающего рентгеновского излучения. Из соотношения для $\omega_{p}^{2}$ плотность электронов проводимости $N$ рассчитывается по формуле

$$
N=\frac{m E_{p}^{2}}{4 \pi \hbar^{2} e^{2}} .
$$

Согласно теории Займана [16], решение уравнений Максвелла для твердого тела в виде плоской, нестационарной электромагнитной волны приводит к модулю волнового вектора $K$, величина которого в общем случае комплексная и выражается соотношением

$$
K=\frac{\omega}{c} \sqrt{\varepsilon+\frac{4 \pi \sigma i}{\omega}}=\frac{\omega n}{c},
$$

где показатель преломления $n$ в этом общем случае является комплексной величиной и с учетом соотношения (6) выражается формулой

$$
n=\sqrt{\varepsilon+\frac{4 \pi \sigma i}{\omega}} .
$$

Оценка мнимого слагаемого в подкоренном выражении для $n: \frac{4 \pi \sigma}{\omega}=\frac{4 \pi}{\rho \omega}$ производится следующим образом. Из табл. 1.2 [13] удельное сопротивление металлов $\rho \sim 10^{-8} \Omega \cdot \mathrm{m}$, а для мягкого рентгеновского излучения угловая частота $\omega \sim 10^{19} \mathrm{~s}^{-1}$, отсюда $\frac{4 \pi}{\rho \omega} \sim 10^{-10} \ll 1$. Поэтому мнимым слагаемым в показателе преломления в металлах для рентгеновского излучения можно смело пренебречь и в дальнейших расчетах пользоваться простейшим соотношением [15]

$$
n=\sqrt{\varepsilon} .
$$

\section{Применение теоретических представлений к полному внешнему отражению рентгеновских лучей от металлов}

ПВО рентгеновских лучей происходит под скользящими углами падения пучка рентгеновских лучей $\alpha$, связанными геометрически с показателем преломления $n$ рентгеновских формулой

$$
n=\cos \alpha .
$$

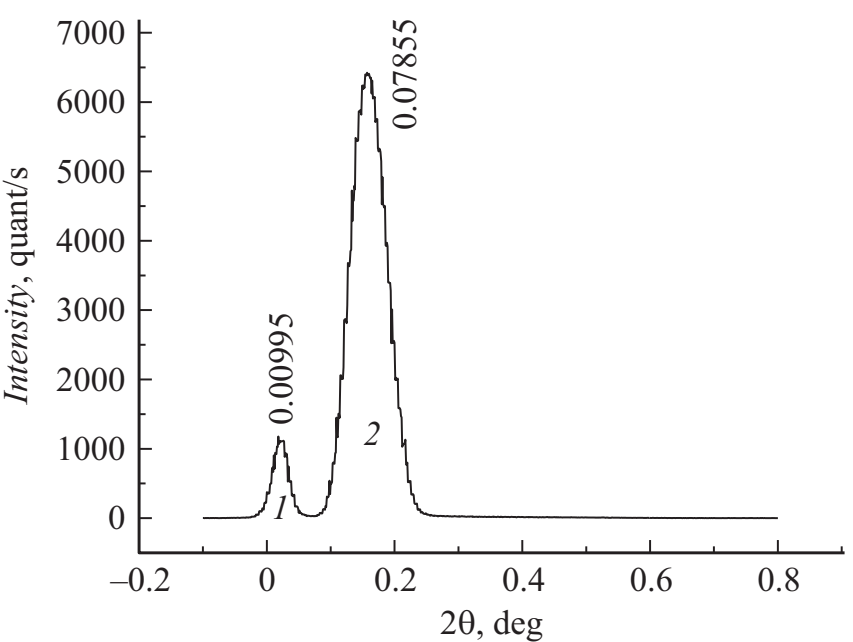

Рис. 1. Рентгенограмма полированного поликристаллического тантала в условиях полного внешнего отражения рентгеновских лучей с указанием скользящих углов падения $\alpha$.

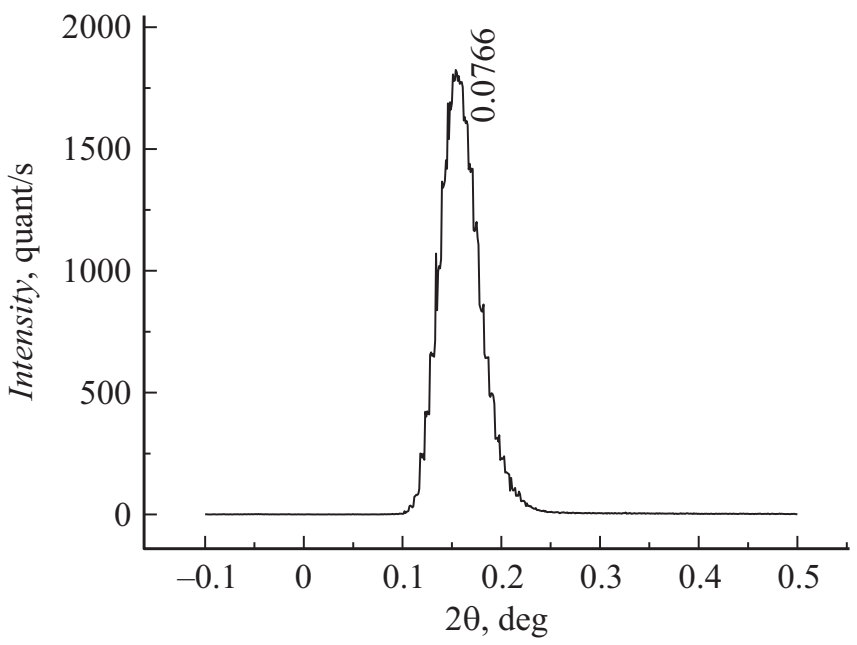

Рис. 2. Рентгенограмма полированного поликристаллического молибдена в условиях полного внешнего отражения рентгеновских лучей с указанием скользящего угла падения $\alpha$.

Из формул (4) и (9) нетрудно определить энергию плазменных колебаний, зная из эксперимента величину скользящего угла падения $\alpha$ пучка рентгеновских лучей, испытавших ПВО:

$$
E_{p}=E \sqrt{1-\cos ^{2} \alpha}=E \cdot \sin \alpha .
$$

Характерной особенностью ПВО рентгеновских лучей является его генетическая связь с теми кристаллитами, кристаллографические плоскости которых параллельны поверхности исследуемого металла [11]. Таким образом, метод ПВО рентгеновских лучей обеспечивает возможность измерения энергий плазмонов и связанных с ними других характеристик твердого тела только в определенных кристаллографических направлениях. Для каждого исследованного металла в определенных 
Данные расчетов твердотельных параметров

\begin{tabular}{c|c|c|c|c|c|c}
\hline Металл & $\alpha^{0}$ & $h k l$ & $E_{p}, \mathrm{eV}$ & $h, \AA$ & $N \cdot 10^{28} \mathrm{~m}^{-3}$ & $E_{\mathrm{F}}, \mathrm{eV}$ \\
\hline $\mathrm{Ni}$ & 0.0099 & 311 & 1.33 & 33.6 & 1.15 & 1.86 \\
& 0.0727 & 200 & 10.21 & 287 & 6.776 & 6.04 \\
$\mathrm{Cu}$ & 0.0178 & 111 & 2.06 & 53 & 4.062 & 4.32 \\
& 0.0261 & 200 & 4.06 & 105 & 8.707 & 7.15 \\
$\mathrm{Mo}$ & 0.0776 & 200 & 10.9 & 84 & 7.723 & 6.64 \\
$\mathrm{Ta}$ & 0.0095 & 200 & 1.40 & 6.46 & 1.274 & 1.98 \\
& 0.0785 & 222 & 11.0 & 50.9 & 7.865 & 6.68 \\
$\mathrm{Pt}$ & 0.0141 & 111 & 1.98 & 5.35 & 2.548 & 3.15 \\
& 0.0878 & 222 & 12.33 & 35.8 & 9.909 & 7.80 \\
$\mathrm{Ag}$ & 0.0124 & 111 & 1.74 & 9.04 & 1.768 & 2.50 \\
$\mathrm{Au}$ & 0.0612 & 111 & 8.60 & 40.2 & 4.807 & 4.78
\end{tabular}

кристаллографических направлениях по формуле (10) вычисляются энергии плазмонов $E_{p}$, а по формуле (5) плотности электронов проводимости $N$.

Из квантовой теории металлов Зоммерфельда [13] для кристаллитов металлов в определенных кристаллографических направлениях вычисляются также энергии Ферми $E_{\mathrm{F}}$ по формуле

$$
E_{\mathrm{F}}=\frac{\hbar^{2}}{2 m}\left(3 \pi^{2} N\right)^{2 / 3}
$$

\section{Результаты расчетов и их обсуждение}

В таблице для ряда металлов и кристаллографических направлений в них приведены результаты расчетов энергий плазменных колебаний $E_{p}$ из экспериментально измеренных скользящих углов падения $\alpha$ рентгеновских лучей, испытавших ПВО, а также плотности электронов проводимости $N$, индексы Миллера $(h k l)$ кристаллографических плоскостей, глубины выхода $h$ рентгеновских лучей, испытавших ПВО, и энергии Ферми $E_{\mathrm{F}}$. Глубину выхода $h$ рассчитывали из практического пробега квантов рентгеновского излучения $\mathrm{Cu} K_{\alpha 1}$ для каждого металла, умноженного на $\sin \alpha$.

Анализ данных, приведенных в таблице, позволяет сделать вывод о наблюдающемся размерном эффекте, выражающемся в увеличении энергии плазмонов, концентрации электронов проводимости и энергии Ферми с ростом глубины выхода $h$ в тех исследованных металлах, которые характеризуются двумя разными показателями преломления рентгеновских лучей (никель, медь, тантал и платина). На рис. 1 в качестве примера приведена рентгенограмма для полного внешнего отражения рентгеновских лучей от поликристаллического полированного тантала с двумя максимумами, соответствующими двум разным показателям преломления рентгеновских лучей, а на рис. 2 в противоположность танталу приведена рентгенограмма для ПВО от поликристаллического полированного молибдена с одним максимумом.

\section{Заключение}

Разработанная методика расчета плазменных колебаний в металлах с помощью ПВО рентгеновских лучей позволяет определять целый ряд характеристик твердого тела, включая энергию плазмонов, концентрацию электронов проводимости, энергию Ферми. Плазмоны с малыми значениями энергии $E_{p} \sim 2 \mathrm{eV}$, возбужденные рентгеновским излучением от некоторых кристаллографических плоскостей таких металлов, как медь, никель, платина, серебро, тантал, могут быть использованы в оптическом поверхностно-плазмонном микроскопе.

\section{Список литературы}

[1] Pines D., Bohm D. // Phys. Rev. 1952. Vol. 85. P. 338-355.

[2] Зубарев Д.Н. // ЖЭТФ. 1953. Т. 25. С. 548-555.

[3] Борзяк Н.Г., Запесочный И.П., Коновалов И.Л. В кн.: Диспергированные металлические пленки. Киев. АН УССР, 1976. C. $104-107$.

[4] Бронштейн И.М., Краинский И.Л. // Изв. АН СССР, сер. физ. 1976. Т. 40. № 8. С. 1656-1658.

[5] Фельдман Л., Майер Джс. Основы анализа поверхности и тонких пленок. М.: Мир, 1989.

[6] Комник Ю.Ф. Физика металлических пленок. М.: Атомиздат, 1979. $263 \mathrm{c}$.

[7] Петров Ю.И. Физика малых частиц. М.: Наука, 1982. $358 \mathrm{c}$.

[8] Климов В.В. Наноплазмоника. М.: Физматлит, 2009. 480 с.

[9] Ramanavieius A., Herberg F.W. Acta Medica Litnavica. 2005. Vol. 12. N 3. P. 1-22.

[10] Бойко М.Е., Шарков М.Д., Конников С.Г., Бобыль А.В., Будкина Н.С. // ЖТФ. 2015. Т. 85. Вып. 11. С. 1-29.

[11] Стожсаров В.М. // ЖТФ. 2017. Т. 87. Вып. 1. С. 125-129.

[12] Стожаров В.М., Пронин В.П. // ЖТФ. 2017. Т. 87. Вып. 12. C. 1901-1905.

[13] Ашкробт Н., Мермин Н. Физика твердого тела. Т. 1. М.: Мир, 1979. 399 с.

[14] Кэй Д., Лэби Т. Справочник физика-экспериментатора. М.: ИЛ, 1969. $420 \mathrm{c}$.

[15] Гроссе П. Свободные электроны в твердых телах. М.: Мир, 1982. 260 с.

[16] Займан Джс. Принципы твердого тела. М.: Мир, 1966. 315 c. 